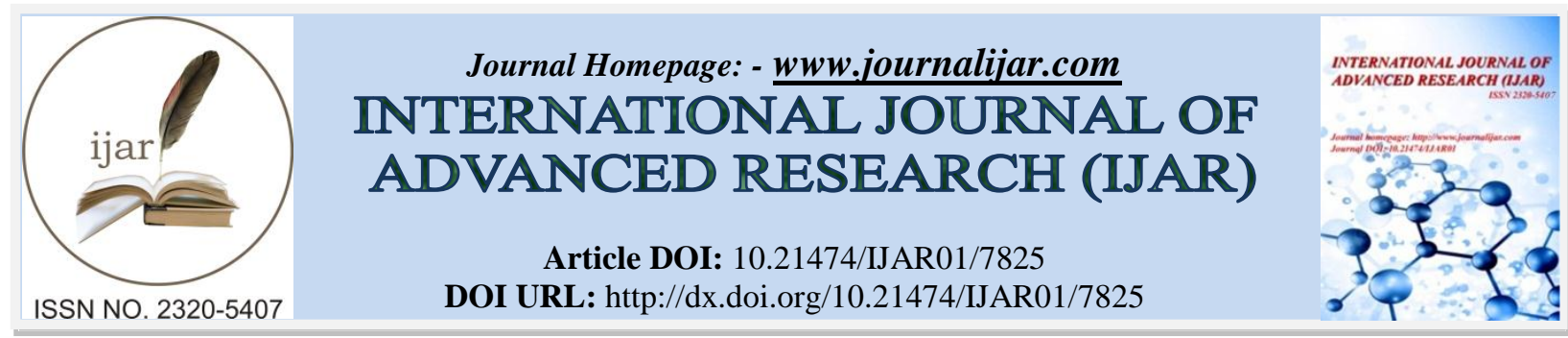

RESEARCH ARTICLE

\title{
FACTORS INFLUENCING EARLY PRIMARY PATENCY OF AV FISTULA IN PEDIATRIC PATIENTS WITH CHRONIC KIDNEY DISEASE.
}

\section{Bakthavatchalam, Sasikumar Sakthivelan and Jayakrishnan Ramakrishnan.}

\section{Manuscript Info}

Manuscript History

Received: 6 August 2018

Final Accepted: 8 September 2018

Published: October 2018

\begin{abstract}
Background: Arteriovenous fistulae (AVF) are the dialysis access modality of choice for patients with end stage renal disease (ESRD). The longer maturation time in children than that in adults and the technical difficulties imposed by small diameters of the vessels are other reasons for a reluctance to create AVFs in children.

Methods: Data abstracted included age, weight, sex, etiology of renal failure, time on dialysis, CVC history, and transplantation history. Patients of age 0 to 15 were included in this study, age was the only inclusion criteria.

Results: Pre operative and prior vene puncture was present in (80\%) patients with primary failure. Greater than 1 previous access failure strong predictor of failure. Surprisingly absence of prior HD was favoring early failure. Intraoperatively poor vein distension $(<2 \mathrm{~mm})$ and post operative Doppler showing absence of spiral laminar flow also predicted early failure in $100 \%$ of the patients.

Conclusion: anatomic factors like vein distension, prior venepuncture highly influence the patency rates. anemia, hypertension and HD benefitted in maintaining patency. proper education of the medical fraternity dealing with peadiatric renal failure patients regarding these factor will help in long term functioning of the fistulas and survival.
\end{abstract}

Copy Right, IJAR, 2018,. All rights reserved.

\section{Introduction:-}

Arteriovenous fistulae (AVF) are the dialysis access modality of choice for patients with end stage renal disease (ESRD) [1,2]. They are associated with a six-fold reduction in the risk of systemic sepsis [3] and lower all cause and cardiovascular mortality than tunneled central venous catheters (TCVCs) [4,5]. For this reason both the UK Renal Association and the Fistula First Initiative in the United States have set targets that two-thirds of incident haemodialysis (HD) patients should commence dialysis via an AVF $[5,6]$.

\section{Methods:-}

Data abstracted included age, weight, sex, etiology of renal failure, time on dialysis, CVC history, and transplantation history. patients of age 0 to 15 were included in this study, age was the only inclusion criteria Etiology of renal failure was identified for each patient and then divided into one of five general categories: 
structural, glomerulonephritis, nephrotic syndrome, metabolic, and other. The creation of each fistula was performed by one of two surgeons, and the type of access created was surgeon-dependent. Vein mapping was performed on all patients and evaluated by each surgeon for suitability of vein size, and in general, the minimum size cutoff was 2.0 $\mathrm{mm}$ for forearm veins and $2.5 \mathrm{~mm}$ for upper arm veins. Owing to the intense vasospastic response of pediatric vessels, repeat intraoperative vein imaging was routinely performed once the patient was placed under anesthesia. All AVFs were performed with a standard end-to-side anastomosis with a continuous running monofilament suture. To decrease the vasospastic response from arterial clamping and vessel dissection, tourniquet occlusion was used for inflow control in selected cases. Loupe magnification was used in all surgical cases. An operating microscope was used by one of the two surgeons on a case-by-case basis as determined by artery size. Patients were seen routinely at 2 and 6 weeks postoperatively for an initial wound check and clearance for use of the fistula.

\section{Results:-}

The mean age of the patients in our study was $10.4 \mathrm{y}$. male and female were equal in number, totally 35 patients were studied and included in the study. they were evaluated for patency in the 2 nd and 6 th week by physical examination. all the patient underwent brachiocephalic fistula with 3 patients undergoing brachiobasilic with primary transposition . there were $3 \mathrm{AV}$ fistula failure within 2 weeks and 2 within 6 weeks. they were classified in to two groups failed and functioning fistula. of the five patients with failure pre operative data, intra operative data and preoperative and post op Doppler finding were analyzed. pre operative hypotension were present in $4 / 5(80 \%)$ patients. prior vane puncture was present in 4/5(80\%). > 1 previous access failure was present in $3 / 5(60 \%)$. sex distribution was equal among the groups. age, height weight, were not significantly influencing the results in both groups. surprisingly absence of prior HD was favoring early failure. intraoperatively poor vein distension $(<2 \mathrm{~mm})$ was present in all cases there by becoming the strong predictor of early failure. post op Doppler showing absence of spiral laminar flow also predicted early failure in $100 \%$ of the patients.

\section{Discussion:-}

The primary patency rates in pediatric populations at 6 months to 2 years have been reported to be as approximately $50 \%-65 \%$, which is similar to the results in adults [6,10-12]. A few recent studies are available showing the excellent outcomes in children [13]. Wartman et al. evaluated the outcomes of 101 AVFs and demonstrated primary and secondary patency rates at 2 years as $83 \%$ and $92 \%$, respectively (14).

Although these documented outcomes are acceptable, some have considered the incidence of primary failure to be sufficiently high to be a barrier for AVF placement in children and adolescents. The longer maturation time in children than that in adults and the technical difficulties imposed by small diameters of the vessels are other reasons for a reluctance to create AVFs in children [11].

Based on such factors, CVCs have remained as the most commonly used access in children on chronic HD . As is With the success of Fistula First Breakthrough Initiative, the prevalence of native AVF was on the rise and the general perception with regard to AVFs had changed (14).

This study showed an acceptable incidence of primary failure. By undertaking careful preoperative evaluation and providing postoperative care, the risk of primary failure can be lowered. proper vein selection is required especially in small children. The patency rates achieved in this study were comparable to those in adult patients [17]. Thus, placement of AVFs in children and adolescents should be actively considered when a permanent vascular access for long-term $\mathrm{HD}$ is required.

Even though endovascular or surgical treatment was required to achieve maturation and early patency, mid- and long-term patency were maintained without the need for frequent interventions. During the first year after AVF creation, active surveillance and timely intervention are important to achieve a favorable outcome.

AVF creation should be considered primarily even in patients with plans for transplantation if a living donor is not available.

Weak arterial inflow and small vein diameter are inevitable in children. Several methods, such as the use of microsurgical techniques, have been attempted to overcome these difficulties and increase patency in small children. Bagolan et al. [10] reported that adoption of microsurgical techniques significantly lowered the primary failure rate. 
Even though we achieved comparable results to that study without using a microscope, we think microsurgical techniques are worth adopting in some subgroups of patients, such as those with low body weight $[10,19,20]$.

Antiplatelet medications and cessation of anti-hypertensive medications were other methods recommended [16]. However, there are few evidences supporting the routine use of antithrombotic therapy. Preoperative duplex is one of the preferred methods to improve AVF maturation rates and highly recommended these days. It may improve outcomes of AVF, although not mandatory [21]. Further study with duplex results is needed to prove the importance of preoperative vein mapping in pediatric patients.

Many patients with failed AVFs were non-compliant to instructions and precautions due to age or mental retardation accompanying the original disease. During the early postoperative period, especially in a pediatric population, close supervision is required so as to not compress the AVF site by bending the arm for a long time. To achieve successful postoperative care and patient education levels, a multidisciplinary team that includes vascular surgeons, nephrologists, and HD nurses is important [15].

\section{Limitations:-}

Small study sample. Lack of statistical analysis. No long term follow up, absence of hypercoagulable work up. Were the limitations in this study.

\section{Conclusion:-}

Creation of AVF for HD in children has peculiar challenges different from adult AV fistulas. demographic factors like, age, sex height weight were not influencing the patency rates. while anatomic factors like vein distension, prior venepuncture highly influence the patency rates. anemia, hypertension and HD benefitted in maintaining patency. proper education of the medical fraternity dealing with peadiatric renal failure patients regarding these factor will help in long term functioning of the fistulas and survival.

\section{References:-}

1. Fogarty D, Cullen R: UK Renal Registry 16th Annual Report. Renal Association [Acceesed online on 12th November 2014: https://www.renalreg. org/wp-content/uploads/2014/09/00a-Introduction.pdf]

2. National Kidney Foundation: KDOQI clinical practice guidelines and clinical practice recommendations for 2006 updates: haemodialysisadequacy, peritoneal dialysis adequacy and vascular access. Am J Kidney Dis 2010, 56:566-577.

3. Thomson PC, Stirling CM, Geddes CC, Morris ST, Mactier RA: Vascular access in haemodialysis patients: a modifiable risk factor for bacteraemia and death. QJM 2007, 100(7):415-422.

4. Bray BD, Boyd J, Daly C, Donaldson K, Doyle A, Fox JG, Innes A, Khan I, Peel RK, Severn A, Shilliday I, Simpson K, Stewart GA, Traynor J, Metcalfe W: Vascular access type and risk of mortality in a national prospective cohort of haemodialysis patients. QJM 2012, 105(11):1097.

5. Fluck R, Kumwenda M: Clinical Practice Guidelines: Vascular Access for Haemodialysis, The Renal Association 5th ed. 2011.

6. Ramage IJ, Bailie A, Tyerman KS, McColl JH, Pollard SG, Fitzpatrick MM. Vascular access sur vival in children and young adults receiving long-term hemodialysis. Am J Kidney Dis 2005;45:708-714.

7. Fadrowski JJ, Hwang W, Neu AM, Fivush BA, Furth SL. Patterns of use of vascular catheters for hemodialysis in children in the United States. Am J Kidney Dis 2009;53:91-98.

8. Hayes WN, Watson AR, Callaghan N, Wright E, Stefanidis CJ; European Pediatric Dialysis Working Group. Vascular access: choice and complications in European paediatric haemodialysis units. Pediatr Nephrol 2012; 27:999-1004.

9. Sidawy AN, Gray R, Besarab A, Henry M, Ascher E, Silva M Jr, et al. Recommended standards for reports dealing with arteriovenous hemodialysis accesses. J Vasc Surg 2002;35: 603-610.

10. Bagolan P, Spagnoli A, Ciprandi G, Picca S, Leozappa G, Nahom A, et al. A ten-year experience of BresciaCimino arteriovenous $\mathrm{f}$ istula in children: technical evolution and refinements. J Vasc Surg 1998;27:640-644.

11. Briones L, Diaz Moreno A, Sierre S, Lopez L, Lipsich J, Adragna M. Permanent vascular access survival in children on long-term chronic hemodialysis. Pediatr Nephrol 2010;25:1731- 1738.

12. Sheth RD, Brandt ML, Brewer ED, Nuchtern JG, Kale AS, Goldstein SL. Permanent hemodialysis vascular access survival in children and adolescents with end-stage renal disease. Kidney Int 2002;62:1864-1869. 
13. Gradman WS, Lerner G, Mentser M, Rodriguez H, Kamil ES. Experience with autogenous arteriovenous access for hemodialysis in children and adolescents. Ann Vasc Surg 2005;19:609- 612.

14. War tman SM, Rosen D, Woo K, Gradman WS, Weaver FA, Rowe V. Outcomes with arteriovenous fistulas in a pediatric population. J Vasc Surg 2014;60:170-174.

15. Chand DH, Bednarz D, Eagleton M, Krajewski L. A vascular access team can increase AV fistula creation in pediatric ESRD patients: a single center experience. Semin Dial 2009; 22:679-683.

16. Manook M, Calder F. Practical aspects of arteriovenous fistula formation in the pediatric population. Pediatr Nephrol 2013;28:885-893.

17. Son HJ, Min SK, Min SI, Park YJ, Ha J, Kim SJ. Evaluation of the efficacy of the forearm basilic vein transposition arteriovenous fistula. J Vasc Surg 2010;51:667-672.

18. Korean Network for Organ Sharing (KONOS). 2014 KONOS Annual Report [Internet]. Seoul: KONOS; 2015 [cited 2015 Sep 15]. Availabe from: https:// www.konos.go.kr.

19. Bourquelot P, Cussenot O, Corbi P, Pillion G, Gagnadoux MF, Bensman A, et al. Microsurgical creation and follow-up of arteriovenous fistulae for chronic haemodialysis in children. Pediatr Nephrol 1990;4:156-159.

20. Sanabia J, Polo JR, Morales MD, Canals MJ, Polo J, Serantes A. Microsurgery in gaining paediatric vascular access for haemodialysis. Microsurgery 1993;14:276-279.

21. Wong CS, McNicholas N, Healy D, Clarke-Moloney M, Coffey JC, Grace PA, et al. A systematic review of preoperative duplex ultrasonography and arteriovenous fistula formation. J Vasc Surg 2013;57:1129-1133. 